REGARDS

SUR LEECONOMIE ALLEMANDE

BULLETIN ECONOMIQUE DU CRAC

\section{Regards sur l'économie allemande}

Bulletin économique du CIRAC

$70 \mid 2005$

Varia

\title{
Industrie : un nouveau patron pour le BDI
}

Isabelle Bourgeois

\section{OpenEdition}

Journals

Édition électronique

URL : http://journals.openedition.org/rea/2283

DOI : $10.4000 /$ rea.2283

ISBN : 978-2-8218-0836-2

ISSN : 1965-0787

Éditeur

CIRAC

Édition imprimée

Date de publication : 1 mars 2005

Pagination : 38

ISSN : 1156-8992

Référence électronique

Isabelle Bourgeois, « Industrie : un nouveau patron pour le BDI », Regards sur l'économie allemande [En ligne], 70 I mars 2005, mis en ligne le 16 décembre 2008, consulté le 15 septembre 2020. URL : http:// journals.openedition.org/rea/2283

Ce document a été généré automatiquement le 15 septembre 2020

(C) CIRAC 


\title{
Industrie : un nouveau patron pour le BDI
}

\author{
Isabelle Bourgeois
}

\section{Retour aux valeurs des PME leaders mondiales}

1 Le 25 janvier, Jürgen R. Thumann (63 ans), a succédé à Michael Rogowski à la tête de la Fédération allemande de l'industrie BDI. Moins médiatique que son prédécesseur connu pour ses formules choc, il incarne aussi le retour des valeurs patronales caractéristiques des PME allemandes (voir REA 69/04). Le groupe Heitkamp \& Thumann KG (Düsseldorf) qu'il avait fondé en 1978 et dont il était resté associé responsable personnellement jusqu'en 1998, figure parmi les $20 \%$ de hidden champions dans le tissu des PME : avec un CA de 300 millions $€$ réalisé par plus de 2000 salariés dans 16 sites (Europe, Asie, continent américain), il est leader mondial dans le segment des composants métalliques et plastiques pour l'industrie automobile, pharmaceutique ou le BTP.

\section{3 chantiers prioritaires : fiscalité, travail, internationalisation}

2 Elu à la tête du BDI pour deux ans, J. R. Thumann défendra les intérêts des PME, notamment en matière de politique fiscale et sociale. Il prône ainsi l'abaissement du taux d'imposition des bénéfices non distribués à $25 \%$ afin d'inciter les entreprises à investir ; son groupe donne l'exemple, investissant cette année 20 millions $€$ et créant 100 emplois en Allemagne. Habitué à une organisation du travail hors du champ de la convention de branche (dans son groupe, la durée hebdomadaire du travail est de 40 heures ou plus), il plaide pour une flexibilisation généralisée des accords sur le temps de travail et la négociation au niveau de l'entreprise plutôt qu'à l'échelle de la branche. 
3 Mais «je ne suis pas un mangeur de syndicats", affirme-t-il (Frankfurter Allgemeine Zeitung, 26-01-05), avançant une raison simple : «le patronat n'est pas en mesure de tenir une grève » . Avec $18 \%$ seulement de capitaux propres en moyenne, et étant donné le haut degré d'interdépendance des activités, les entreprises sont peu enclines au conflit, lui préférant de loin la négociation. Enfin, son troisième dossier : l'internationalisation des activités des PME, dans l'intérêt même de l'emploi et de la croissance de l'Allemagne.

\section{Le BDI, un puissant lobby}

Le BDI est l'une des institutions de cette triade décisionnelle (gouvernement, patronat, syndicats) qui définit la politique économique et sociale et constitue le fondement de la forme négociée du capitalisme qui prévaut outre-Rhin. Si le BDI ne représente pas les intérêts organisés $d u$ patronat face au DGB dans l'équilibre politique des représentations (le partenaire de la confédération syndicale est alors la Fédération patronale BDA), il n'en représente pas moins ceux du monde de l'entreprise, et plus particulièrement de l'industrie (voir REA 60/03). Le BDI, qui fédère 36 fédérations de branche, compte quelque 100000 entreprises affiliées, employant directement et indirectement (par diffusion) près de la moitié des actifs occupés d'Allemagne. Les PME allemandes ont là un puissant lobby. (IB)

\section{INDEX}

Mots-clés : Industrie, BDI, lobby, syndicat 